\title{
PENGARUH KUALITAS PELAYANAN DAN KEPUASAN PELANGGAN TERHADAP LOYALITAS NASABAH PT BANK RAKYAT INDONESIA CABANG PADANG
}

\author{
Nazarudin Aziz, Yosep Eka Putra \\ Sekolah Tinggi Ilmu Ekonomi "KBP” Padang \\ nazarudinaziz@akbpstie.ac.id
}

\begin{abstract}
The aim of this study is to analyze the influence of service quality and customer satisfaction to customer loyalty at PT. Bank Rakyat Indonesia of Padang Branch Office. Samples are taken using Proportionate Cluster Random Sampling obtained of 100 customers. The study instrument is using questionnaire. The data is analyzed using Path Analysis. The result of the study showed that there is significant influence of service quality and customer satisfaction to customer loyalty. The influence of service quality to customer satisfaction is $61,5 \%$, and the influence of service quality to customer loyalty is $54,6 \%$. It is recommended to PT. Bank Rakyat Indonesia of Padang Branch Office to increase its service quality and customer satisfaction, because this study has proven that these variables have influenced to customer loyalty.
\end{abstract}

Keywords: Service quality, customer satisfaction, customer loyalty

\section{PENDAHULUAN}

Pada industri perbankan yang tumbuh dan bertambah sejak kebijakan 27 Oktober 1988 (Pakto 88), menawarkan berbagai jenis produk dan jasa perbankan. Kemudahan mendirikan bank dan membuka jaringan kantor cabang, gencarnya promosi dan pemasangan iklan, serta penawaran produk tabungan berhadiah menyebabkan usaha perbankan menghadapi persaingan yang ketat. Dalam upaya meningkatkan daya saing, pihak bank harus mengembangkan dan meningkatkan pelayanannya menjadi pelayanan unggul atau prima (service excellence).

Dalam prakteknya produk bank adalah pelayanan dalam bidang keuangan. Layanan transaksi keuangan yang diberikan secara langsung memberikan nilai tambah kepada nasabah. Pada tahap awal keberhasilan suatu bank dalam bersaing antara lain ditentukan keunggulan produk dan gencarnya promosi. Namun hal tersebut hanya dapat dipertahankan dan dikembangkan oleh sikap para karyawan bank dalam melaksanakan pelayanan unggul atau prima kepada nasabahnya. Dalam hal ini bagaimana cara karyawan bank memperlakukan nasabah sedemikian rupa sehingga ia memperoleh persepsi yang positif dari nasabah.

Dari 21 bank yang beroperasional di Kota Padang saat ini BRI merupakan salah satu bank yang tertua di Kota Padang, secara perlahan tentunya Bank BRI ini akan merebut pangsa pasar bank yang sama-sama beroperasi di Kota Padang. Pertumbuhan posisi jumlah nasabah yang ada pada Bank BRI Cabang Padang 
Sejak Tahun 2007 s/d 2011 seperti tabel di bawah ini.

\section{Tabel 1}

Jumlah Nasabah Periode 2007 s/d 2011

\begin{tabular}{|l|r|r|r|r|r|r|}
\hline Jenis Tabungan & \multicolumn{1}{|c|}{2007} & \multicolumn{1}{c|}{2008} & \multicolumn{1}{c|}{2009} & \multicolumn{1}{c|}{2010} & \multicolumn{1}{c|}{2011} & \multicolumn{1}{c|}{2012} \\
\hline Giro & 198 & 167 & 182 & 173 & 1.165 & 2.378 \\
\hline Tabungan & 2.397 & 2.133 & 2.310 & 2.177 & 2.195 & 3.498 \\
\hline Deposito & 228 & 267 & 265 & 2.660 & 2.451 & 3.375 \\
\hline Kredit & 2.123 & 2.067 & 2.157 & 2.336 & 2.625 & 3.250 \\
\hline Jumlah & 4.946 & 4.634 & 4.914 & 7.346 & 8.436 & 12.501 \\
\hline
\end{tabular}

Sumber : Bank Rakyat Indonesia Cabang Padang Tahun 2012

Berdasarkan tabel di atas, terlihat secara keseluruhan bahwa jumlah penabung dari tahun 2007 ke tahun 2008 menurun sebesar 9,06\%, sedangkan pada tahun 2009 terjadi peningkatan sebesar 7,40\%, namun untuk tahun 2010 dan 2011 selalu terjadi penurunan masing-masing sebesar $5,11 \%$ dan $0,42 \%$. Hal ini diduga karena terjadinya perpindahan nasabah ke bank lain dengan menarik dana tabungannya serta menutup rekening tabungannya pada Bank BRI Cabang Padang. Hal ini akan menyebabkan Bank BRI Cabang Padang kekurangan dana dan terganggunya likuiditas bank. Sehingga terjadi penurunan minat bertransaksi kembali nasabah pada Bank BRI Cabang Padang.

Berdasarkan permasalahan di atas, perlu ditelaah lebih lanjut pengaruhnya terhadap minat bertransaksi kembali nasabah dalam menempatkan dananya di Bank BRI Cabang Padang. Penulis tertarik untuk menelitinya dalam bentuk tesis yang diberi judul: "Pengaruh Kualitas Pelayanan dan Kepuasan Pelanggan Terhadap Loyalitas Nasabah PT Bank Rakyat Indonesia Cabang Padang."

\section{Loyalitas Nasabah}

Oliver (1996:392) dalam Hurriyati (2005:70) mengungkapkan definisi Loyalitas Pelanggan adalah komitmen pelanggan bertahan secara mendalam untuk berlangganan kembali atau melakukan pembelian ulang produk/ jasa terpilih secara konsisten di masa yang akan datang, meskipun pengaruh situasi dan usahausaha pemasaran mempunyai potensi untuk menyebabkan perubahan perilaku.

Kertajaya (2005:54) mendefinisikan loyalitas sebagai perilaku konsumen yang melakukan pembelian ulang (repeat), mereferensikan produk atau jasa yang digunakan kepada orang lain (revere) dan bersikap kebal terhadap godaan produk lain (immune).

Tjiptono (2001:85) mengemukakan enam indikator yang bisa digunakan untuk mengukur loyalitas kaonsumen yaitu 1) Pembelian ulang; 2) kebiasaan mengkonsumsi merek tersebut; 3) selalu menyukai merek tersebut; 4) tetap mamilih merek tersebut; 5) yakin bahwa merek tersebut yang terbaik; 6) merekomendasikan merek tersebut pada orang lain

Bank sebagai perusahaan yang bergerak di bidang jasa dengan konsumen yang dikenal dengan istilah nasabah, dalam hal loyalitas konsumen maka yang dimaksud adalah loyalitas nasabah. Loyalitas konsumen salah satu cirinya adalah pembelian berulang, maka dalam perbankan adalah penabungan berulang (repeat transaction).

\section{Kepuasan Pelanggan}

Engel dalam Tjiptono (2000) mengungkapkan bahwa kepuasan pelanggan merupakan evaluasi purna beli dimana alternatif yang dipilih sekurang-kurangnya memberikan hasil (outcome) sama atau melampaui harapan pelanggan, sedangkan 
ketidakpuasan timbul apabila hasil yang diperoleh tidak memenuhi harapan pelanggan.

Selanjutnya menurut Kotler (2002:38) kepuasan pelanggan adalah perasaan senang atau kecewa seseorang yang berasal dari perbandingan kesannya terhadap kinerja (hasil) suatu produk dan harapan-harapan. Pengertian kepuasan pelanggan menurut Oliver dalam Suprapto (1980) adalah tingkat perasaan seseorang setelah membandingkan kinerja perusahaan dengan harapan.

Menurut Tjiptono (2002 : 24) terciptanya kepuasan dapat memberikan beberapa manfaat diantaranya hubungan antara perusahaan dan pelanggan menjadi harmonis, memberi dasar bagi pembelian ulang dan menciptakan loyalitas pelanggan serta rekomendasi dari mulut ke mulut yang menguntungkan perusahaan.

Cara pengukuran kepuasan pelanggan menurut Kotler, et al, (Tjiptono, 2001: 34), ada empat metode yang digunakan dalam mengukur tingkat kepuasan pelanggan antara lain 1) sistem keluhan dan saran, 2) ghost shopping, 3) Lost customer analysis, 4) survey kepuasan pelanggan.

\section{Kualitas Pelayanan}

Tjiptono (1996:54) "kualitas pelayanan mempunyai hubungan yang erat dengan kepuasan pelanggan. Kualitas memberikan suatu dengan kepuasan pelanggan. Kualitas memberikan suatu dorongan kepada pelanggan untuk menjalin hubungan yang kuat dengan perusahaan”.

Menurut Parasuraman dan kawan-kawan, dalam Tjiptono (2005 :134) mengemukakan lima dimensi pokok yang digunakan dalam menilai suatu kualitas pelayanan pada perusahaan jasa, meliputi :

a. Bukti fisik (tangibles), berkenaan dengan daya tarik fasilitas fisik, perlengkapan dan material yang digunakan perusahaan, serta penampilan karyawan.

b. Keandalan (reliability), berkaitan dengan kemampuan perusahaan untuk memberikan layanan yang akurat sejak pertama kali tanpa membuat kesalahan apapun dan menyampaikan jasanya sesuai dengan waktu yang disepakati.

c. Daya tangkap (responsiveness), berkenaan dengan kesediaan dan kemampuan para karyawan untuk membantu para pelanggan dan merespon permintaan mereka, serta menginformasikan kapan saja akan diberikan dan kemudian memberikan jasa secara cepat.

d. Jaminan (assurance), yakni perilaku para karyawan mampu menumbuhkan kepercayaan pelanggan terhadap perusahaan dan perusahaan bisa menciptakan rasa aman bagi pelanggannya. Jaminan juga berarti bahwa para karyawan selalu bersikap sopan dan menguasai pengetahuan dan keterampilan yang dibutuhkan untuk mengenai setiap pertanyaan atau masalah pelanggan.

e. Empati (empathy), berarti perusahaan memahami masalah para pelanggannya dan bertindak demi kepentingan pelanggan, serta memberikan perhatian personal kepada para pelanggan dan memiliki jam operasi yang nyaman.

\section{Hubungan Kualitas Pelayanan dengan Kepuasan Nasabah}

Suprapto (1980:44) menyatakan bahwa kepuasan pelanggan akan tercapai jika mengkonsumsi barang atau jasa, hasil yang dirasakan pelanggan memenuhi atau melampaui harapannya maka ia akan memutuskan untuk membeli ulang (berlangganan). Kepuasan pelanggan adalah persepsi pelanggan mengenai mutu suatu barang atau jasa dan kepuasan menyeluruh, mereka memiliki beberapa 
indikator/petunjuk yang bisa dilihat. Pelanggan akan mengatakan hal-hal yang bagus tentang barang atau jasa dan tersenyum ketika berbicara mengenai barang atau jasa.

\section{Hubungan Kualitas Pelayanan dengan Loyalitas Pelanggan}

Loyalitas ini akan direspon jika pelayanan yang diberikan berkualitas. Sebaliknya, jika pelanggan atau nasabah merasa dirugikan akibat pelayanan yang berbelit-belit, tidak terbuka/transparan tentang apa yang diinginkan oleh aparat itu maka dapat dikatakan pelayanannya tidak berkualitas. Untuk itu peningkatan kualitas pelayanan harus terus ditingkatkan sehingga mitra kerja dapat merasakan kualitas pelayanan yang diberikan dalam menjalankan setiap transaksi yang berakibat akan menyebabkan konsumen itu menjadi loyal.

\section{Kerangka Konseptual}

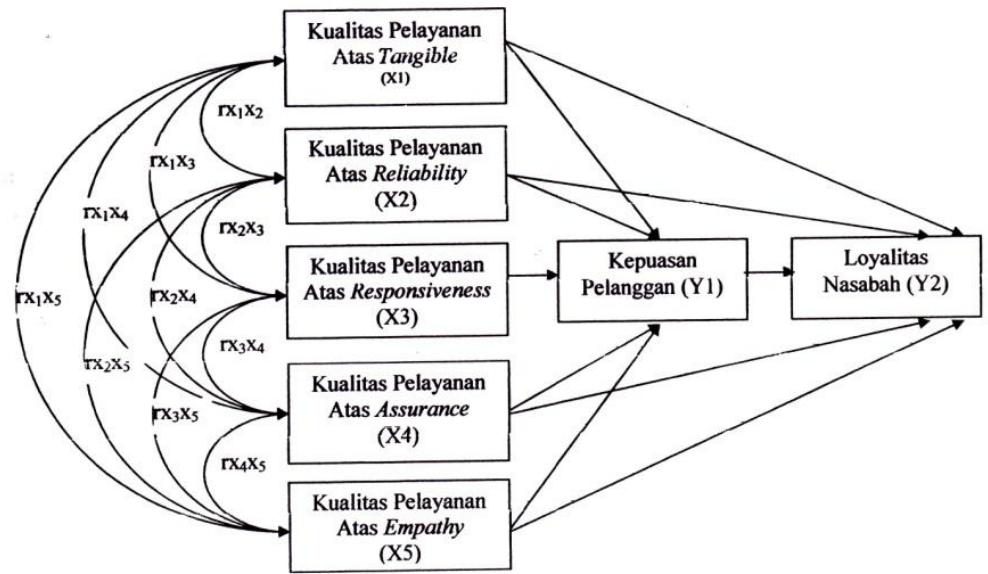

\section{Hipotesis}

\section{Gambar Kerangka Konseptual}

1. Kualitas Pelayanan dengan dimensi Tangibles (bukti tisik), Reliability (keandalan), Responsiveness (daya tanggap), Assurance (jaminan), dan Empathy (empati) berpengaruh signifikan terhadap kepuasan nasabah pada Bank BRI Cabang Padang.

2. Kualitas Pelayanan dengan dimensi Tangibles (bukti fisik), Reliability (keandalan), Responsiveness (daya tanggap), Assurance (jaminan), Empathy (empati) dan kepuasan nasabah berpengaruh signifikan terhadap loyalitas nasabah nada Bank BRI Cabang Padang.

\section{METODE PENELITIAN \\ Jenis Rancangan Penelitian}

Jenis rancangan penelitian ini adalah explanatory dimana peneliti melakukan presentasi atas nasabah Bank Rakyat Indonesia Kantor Cabang Padang baik nasabah dana (penabung, deposan, giran) maupun nasabah kredit (debitur).

\section{Populasi Dan Sampel}

Populasi yang digunakan dalam penelitian ini adalah nasabah atau mitra kerja PT. Bank Rakyat Indinesia Kantor Cabang Padang yang bersifat populasi heterogen berupa mitra kerja Tabungan, Deposito, Giro dan Kredit per 30 Desember 2012 dengan total populasi sebanyak 12.501.

Jumlah sampel didapatkan dengan menggunakan rumus Slovin dalam Umar (1999:49) yaitu $\mathrm{n}=\mathrm{N} /\left(1+\mathrm{Ne}^{2}\right)$, sebanyak 99,28 atau dibulatkan menjadi 100 orang. 


\section{Teknik pengambilan sample}

Teknik pengambilan sampel dengan menggunakan metode Proportionate Cluster Random Sampling didapatkan untuk nasabah Tabungan 28 orang, Deposito 27 orang, Giro 19 orang, dan kredit 26 orang, sehingga total menjadi 100 orang.

\section{Lokasi dan waktu penelitian}

Lokasi penelitian adalah di Kota Padang, dengan pertimbangan sebagai tempat domisili penulis untuk menghemat waktu dan biaya selama penelitian yaitu pada bulan April 2013.

\section{Variabel penelitian}

Variabel penelitian disini adalah semua variable yang terlibat dalam judul penelitian yang penulis gunakan dalam penelitian dan diuraikan menurut indikatornya yaitu variable bebas (exogen) dan variable terikat (endogen) adapun variable tersebut adalah :

Tabel 2

\section{Identifikasi Variabel}

\begin{tabular}{|c|c|c|c|}
\hline No & Variabel & Indikator & Skala \\
\hline 1. & $\begin{array}{l}\text { Loyalitas nasabah } \\
\text { (Y) }\end{array}$ & $\begin{array}{ll}- & \text { Frekuensi kunjungan } \\
\text { - } & \text { Tidak mudah beralih } \\
\text { - } & \text { Promosi dari mulut ke mulut } \\
\text { - } & \text { Menyampaikan saran-saran } \\
\text { - } & \text { Pembelaan }\end{array}$ & Likert \\
\hline 2. & $\begin{array}{l}\text { Kualitas Pelayanan } \\
\text { dengan dimensi } \\
\text { Tangible (X1) }\end{array}$ & $\begin{array}{ll}- & \text { Peralatan modern } \\
\text { - } & \text { Lokasi } \\
\text { - } & \text { Fasilitas yang bersifat visual } \\
\text { - } & \text { Keadaan parkir } \\
\text { - } & \text { Penampilan karyawan }\end{array}$ & Likert \\
\hline 3. & $\begin{array}{l}\text { Kualitas Pelayanan } \\
\text { dengan dimensi } \\
\text { Reliability (X2) }\end{array}$ & $\begin{array}{ll}\text { - } & \text { Pelayanan sesuai janji } \\
\text { - } & \text { Pemberian layanan yang cepat dan tepat } \\
\text { - } & \text { Tepat waktu } \\
\text { - } & \text { Menyimpan catatan/dokumen }\end{array}$ & Likert \\
\hline 4. & $\begin{array}{l}\text { Kualitas Pelayanan } \\
\text { dengan dimensi } \\
\text { Responsiveness } \\
\text { (X3) }\end{array}$ & $\begin{array}{ll}\text { - } & \text { Layanan yang cepat } \\
\text { - } & \text { Kesediaan membantu } \\
\text { - } & \text { Kesediaan merespon permintaan } \\
& \text { nasabah }\end{array}$ & Likert \\
\hline 5. & $\begin{array}{l}\text { Kualitas Pelayanan } \\
\text { dengan dimensi } \\
\text { Assurance }(\mathrm{X} 4)\end{array}$ & $\begin{array}{ll}\text { - } & \text { Menumbuhkan rasa percaya } \\
\text { - } & \text { Membuat nasabah merasa aman } \\
\text { - } & \text { Konsisten bersikap sopan }\end{array}$ & Likert \\
\hline 6. & $\begin{array}{l}\text { Kualitas Pelayanan } \\
\text { dengan dimensi } \\
\text { Empathy (X5) }\end{array}$ & $\begin{array}{ll}\text { - } & \text { Perhatian } \\
\text { - } & \text { Kepentingan nasabah } \\
\text { - } & \text { Kebutuhan nasabah } \\
\text { - } & \text { Sikap ramah }\end{array}$ & Likert \\
\hline 7. & $\begin{array}{l}\text { Kepuasan Nasabah } \\
\text { atas Kualitas } \\
\text { Pelayanan (X6) }\end{array}$ & $\begin{array}{ll}\text { - } & \text { Lokasi strategik } \\
\text { - } & \text { Pemberian suku bunga } \\
\text { - } & \text { Variasi produk } \\
\text { - } & \text { Menyampaikan saran-saran } \\
\text { - } & \text { Pembelaan }\end{array}$ & Likert \\
\hline
\end{tabular}




\section{Uji Validitas dan Reliabilitas}

Uji validitas menggunakan metode korelasi Pearson Product Moment. Sedangkan uji reliabilitas dengan teknik Cronbach Alpha.

\section{Jenis Dan Metode Pengumpulan Data}

\section{Data Primer}

Data primer merupakan data yang didapat dari sumber pertama dan dalam hal ini data didapat dari kuesioner dimana data ini merupakan data mentah yang akan diproses lebih lanjut. Data ini berisikan antara lain berisikan pendapat dari nasabah BRI Kantor Cabang Padang tentang kepuasan dari pelayanan yang diberikan dengan membandingkan antara harapan dan kenyataan dari pelayanan yang diterima.

\section{Data Skunder}

Data skunder merupakan data primer yang telah diolah lebih lanjut sehingga lebih informatif jika dipergunakan oleh pihak lain dan dalam hal ini data skunder didapat dari Pimpinan, Staff serta buletin PT. Bank Rakyat Indonesia Cabang Padang.

\section{Tehknik Pengumpulan Data}

Untuk mendapatkan data yang diperlukan dalam penelitian ini dilakukan cara-cara pengumupulan data meliputi kuesioner, wawancara, dan dokumentasi bank.

\section{Tehnik Analisis Data}

Pengolahan data kuisioner yang terkumpul dikelompokan kedalam 3 (tiga) langkah yaitu :

1. Persiapan

Persiapan merupakan langkah pengolahan data dengan mengumpulkan dan memeriksa perlengkapan lembaran kuisioner dan setelah itu memeriksa kebenaran pengisiannya.

2. Tabulasi

Setelah persiapan data setelesai dilaksanakan maka data tersebut ditabulasikan memberikan nilai atau skoring sesuai dengan sistim penilaian yang telah ditetapkan yaitu dengan kuisoner dengan mengunakan transformasi successive method. Data hasil tabulasi dianalisis dengan pendekatan penelitian yang digunakan sesuai dengan tujuan penelitian yaitu untuk mengetahui pengaruh Kualitas pelayanan dengan dimensi Tangibles (bukti tisik), Reliability (keandalan), Responsiveness (daya tanggap), Assurance (jaminan), dan Empathy (empati) terhadap minat bertransaksi kembali.

3. Pengolahan

Pengolahan data dilakukan menggunakan program SPSS. Pertamatama dilakukan uji validitas dan reliabilitas, kemudian dilanjutkan dengan analisis data dengan teknik Analis Jalur (Path Analysis) untuk meneliti hubungan antar variabel, besarnya pengaruh masing masing variabel dan variabel mana yang punya pengaruh langsung ataupun pengaruh tidak langsung seperangkat variabel penyebab (variabel eksogen) terhadap variabel akibat (variabel endogen).

Hasil besaran diagram jalur menunjukan besarnya pengaruh masing masing variabel penyebab terhadap variabel akibat yang disebut koefisien jalur dengan persamaan strukturnya adalah :

$$
\mathrm{Y}=\mathrm{P}_{\mathrm{yx} 1} \mathrm{X}_{1}+\mathrm{P}_{\mathrm{yx} 2} \mathrm{X}_{2}+\mathrm{P}_{\mathrm{yx} 3} \mathrm{X}_{3}+\mathrm{P}_{\mathrm{yx} 4} \mathrm{X}_{4}+\mathrm{P}_{\mathrm{yx} 5} \mathrm{X}_{5}+\varepsilon
$$


Adapun uji statistik yang dilakukan adalah :

1) Uji F, yaitu untuk mengetahui pengaruh secara keseluruhan variabel penyebab terhadap variabel akibat, dengan keputusan jika $\mathrm{F}$ hitung $>\mathrm{F}$ tabel, maka Ho ditolak

2) Uji t, yaitu untuk mengetahui pengaruh secara individu variabel penyebab terhadap variabel akibat dengan keputusan jika $\mathrm{t}$ hitung $>\mathrm{t}$ tabel, maka koefisien jalur secara statisitik bermakna (signifikan).

\section{HASIL PENELITIAN DAN PEMBAHASAN \\ Karakteristik Responden}

Tabel 3

Karakteristik Responden Jenis Kelamin

\begin{tabular}{|c|l|c|c|}
\hline No & \multicolumn{1}{|c|}{ Jenis Kelamin } & Frekuensi & Persentase \\
\hline 1 & Laki-laki & 30 & 30 \\
\hline 2 & Perempuan & 70 & 70 \\
\hline & Jumlah & 100 & 100 \\
\hline
\end{tabular}

Sumber: Pengolahan data primer, 2013

\section{Tabel 4}

Karakteristik Responden berdasarkan Tingkat Pendidikan

\begin{tabular}{|c|l|c|c|}
\hline No & \multicolumn{1}{|c|}{ Tingkat Pendidikan } & Frekuensi & Persentase \\
\hline 1 & SMA & 50 & 50 \\
\hline 2 & Diploma & 25 & 25 \\
\hline 3 & Sarjana & 15 & 15 \\
\hline 4 & Pascasarjana & 10 & 10 \\
\hline & Jumlah & 100 & 100 \\
\hline
\end{tabular}

Sumber: Pengolahan data primer, 2013

Tabel 5

Karakteristik Responden berdasarkan Jenis Pekerjaan

\begin{tabular}{|c|l|c|c|}
\hline No & \multicolumn{1}{|c|}{ Tingkat Pendidikan } & Frekuensi & Persentase \\
\hline 1 & Wiraswasta & 15 & 15 \\
\hline 2 & Pegawai Swasta & 60 & 60 \\
\hline 3 & Pegawai BUMN/BUMD & 5 & 5 \\
\hline 4 & PNS & 20 & 20 \\
\hline & Jumlah & 100 & 100 \\
\hline
\end{tabular}

Sumber: Pengolahan data primer, 2013

Deskripsi Variabel Penelitian

Tabel 6

Deskripsi Variabel Loyalitas Nasabah (Y)

\begin{tabular}{|c|l|c|c|c|}
\hline No & \multicolumn{1}{|c|}{ Indikator } & Rata-rata & TCR (\%) & Kategori \\
\hline 1 & Frekuensi kunjungan & 3,41 & 68,12 & Cukup \\
\hline 2 & Tidak mudah beralih & 3,44 & 68,48 & Cukup \\
\hline 3 & Promosi dari mulut ke mulut & 3,65 & 72,90 & Cukup \\
\hline 4 & Menyampaikan saran-saran & 3,69 & 73,86 & Cukup \\
\hline 5 & Pembelaan & 3,51 & 70,14 & Cukup \\
\hline & Rata-rata Total & $\mathbf{3 , 5 4}$ & $\mathbf{7 0 , 7 7}$ & Cukup \\
\hline
\end{tabular}

Sumber: Pengolahan data primer, 2013 
Berdasarkan tabel diatas skor rata-rata variabel loyalitas adalah sebesar 3,54 dengan tingkat capaian responden (TCR) sebesar 70,77\%. Hal ini menunjukkan loyalitas nasabah masuk dalam kategori cukup. Dengan demikian disimpulkan nasabah mempunyai loyalitas yang cukup terhadap PT. Bank Rakyat Indonesia Cabang Padang.

Tabel 7

Deskripsi Variabel Tangible (X1)

\begin{tabular}{|c|l|c|c|c|}
\hline No & \multicolumn{1}{|c|}{ Indikator } & Rata-rata & TCR (\%) & Kategori \\
\hline 1 & Peralatan modern & 3,94 & 78,73 & Cukup \\
\hline 2 & Lokasi bersifat & 4,17 & 83,46 & Baik \\
\hline 3 & $\begin{array}{l}\text { Fasilitas yang } \\
\text { visual }\end{array}$ & 4,30 & 86,08 & Baik \\
\hline 4 & Keadaan parkir & 4,13 & 85,05 & Baik \\
\hline 5 & Penampilan karyawan & $\mathbf{4 , 1 6}$ & $\mathbf{8 3 , 1 7}$ & Baik \\
\hline & Rata-rata Total
\end{tabular}

Sumber: Pengolahan data primer, 2013

Berdasarkan tabel diatas skor rata-rata variabel tangible adalah sebesar 4,16 dengan tingkat capaian responden (TCR) sebesar 83,17\%. Hal ini menunjukkan tangible masuk dalam kategori baik. Dengan demikian disimpulkan nasabah mempunyai tingkat kepuasan yang baik atas dimensi tangible pada PT. Bank Rakyat Indonesia Cabang Padang.

Tabel 8

Deskripsi Variabel Reliability (X2)

\begin{tabular}{|c|l|c|c|c|}
\hline No & \multicolumn{1}{|c|}{ Indikator } & Rata-rata & TCR (\%) & Kategori \\
\hline 1 & Pelayanan sesuai janji & 3,65 & 72,90 & Cukup \\
\hline 2 & $\begin{array}{l}\text { Pemberian layanan yang cepat dan } \\
\text { tepat }\end{array}$ & 3,43 & 68,60 & Cukup \\
\hline 3 & Tepat waktu & 3,37 & 67,36 & Cukup \\
\hline 4 & Menyimpan catatan/dokumen & 3,41 & 68,12 & Cukup \\
\hline & Rata-rata Total & $\mathbf{3 , 4 6}$ & $\mathbf{6 9 , 2 5}$ & Cukup \\
\hline
\end{tabular}

Sumber: Pengolahan data primer, 2013

Berdasarkan tabel diatas skor rata-rata variabel reliability adalah sebesar 3,46 dengan tingkat capaian responden (TCR) sebesar 69,25\%. Hal ini menunjukkan reliability masuk dalam kategori cukup. Dengan demikian disimpulkan nasabah mempunyai tingkat kepuasan yang cukup atas dimensi reliability pada PT. Bank Rakyat Indonesia Cabang Padang

\section{Tabel 9}

Deskripsi Variabel Responsiveness (X3)

\begin{tabular}{|c|l|c|c|c|}
\hline No & \multicolumn{1}{|c|}{ Indikator } & Rata-rata & TCR (\%) & Kategori \\
\hline 1 & Layanan yang cepat & 2,69 & 53,74 & Cukup \\
\hline 2 & Kesediaan membantu & 2,63 & 52,56 & Cukup \\
\hline 3 & $\begin{array}{l}\text { Kesediaan merespon } \\
\text { permintaan nasabah }\end{array}$ & 3,26 & 65,26 & Cukup \\
\hline & Rata-rata Total & $\mathbf{2 , 8 6}$ & $\mathbf{5 7 , 1 9}$ & Cukup \\
\hline
\end{tabular}

Sumber: Pengolahan data primer, 2013

Berdasarkan tabel diatas skor rata-rata variabel responsiveness adalah sebesar 2,86 dengan tingkat capaian responden (TCR) sebesar 57,19\%. Hal ini 
menunjukkan responsiveness masuk dalam kategori cukup. Dengan demikian disimpulkan nasabah mempunyai tingkat kepuasan yang cukup atas dimensi responsiveness pada PT. Bank Rakyat Indonesia Cabang Padang.

\section{Tabel 10}

Deskripsi Variabel Assurance (X4)

\begin{tabular}{|c|l|c|c|c|}
\hline No & \multicolumn{1}{|c|}{ Indikator } & Rata-rata & TCR (\%) & Kategori \\
\hline 1 & Menumbuhkan rasa percaya & 3,39 & 67,88 & Cukup \\
\hline 2 & Membuat nasabah merasa aman & 3,21 & 64,25 & Cukup \\
\hline 3 & Konsisten bersikap sopan & 3,23 & 64,64 & Cukup \\
\hline & Rata-rata Total & $\mathbf{3 , 2 8}$ & $\mathbf{6 5 , 5 9}$ & Cukup \\
\hline
\end{tabular}

Sumber: Pengolahan data primer, 2013

Berdasarkan tabel diatas skor rata-rata variabel assurance adalah sebesar 3,28 dengan tingkat capaian responden (TCR) sebesar 65,59\%. Hal ini menunjukkan assurance masuk dalam kategori cukup. Dengan demikian disimpulkan nasabah mempunyai tingkat kepuasan yang cukup atas dimensi assurance pada PT. Bank Rakyat Indonesia Cabang Padang.

Tabel 11

Deskripsi Variabel Empathy (X5)

\begin{tabular}{|c|l|c|c|c|}
\hline No & \multicolumn{1}{|c|}{ Indikator } & Rata-rata & TCR (\%) & Kategori \\
\hline 1 & Perhatian & 3,33 & 66,59 & Cukup \\
\hline 2 & Kepentingan nasabah & 3,32 & 66,42 & Cukup \\
\hline 3 & Kebutuhan nasabah & 3,34 & 66,78 & Cukup \\
\hline 4 & Sikap ramah & 3,43 & 68,60 & \\
\hline & Rata-rata Total & $\mathbf{3 , 3 5}$ & $\mathbf{6 7 , 1 0}$ & Cukup \\
\hline
\end{tabular}

Sumber: Pengolahan data primer, 2013

Berdasarkan tabel diatas skor rata-rata variabel empathy adalah sebesar 3,35 dengan tingkat capaian responden (TCR) sebesar 67,10\%. Hal ini menunjukkan empathy masuk dalam kategori cukup. Dengan demikian disimpulkan nasabah mempunyai tingkat kepuasan yang cukup atas dimensi empathy pada PT. Bank Rakyat Indonesia Cabang Padang.

Tabel 12

Deskripsi Variabel Kepuasan Nasabah (X6)

\begin{tabular}{|c|l|c|c|c|}
\hline No & \multicolumn{1}{|c|}{ Indikator } & Rata-rata & TCR (\%) & Kategori \\
\hline 1 & Lokasi strategik & 3,62 & 72,35 & Cukup \\
\hline 2 & Pemberian suku bunga & 3,32 & 66,46 & Cukup \\
\hline 3 & Variasi produk & 3,51 & 70,10 & Cukup \\
\hline 4 & Menyampaikan saran-saran & 3,44 & 68,78 & \\
\hline 5 & Pembelaan & 3,34 & 66,76 & \\
\hline & Rata-rata Total & $\mathbf{3 , 4 5}$ & $\mathbf{6 8 , 9 1}$ & Cukup \\
\hline
\end{tabular}

Sumber: Pengolahan data primer, 2013

Berdasarkan tabel diatas skor rata-rata variabel kepuasan nasabah adalah sebesar 3,45 dengan tingkat capaian responden (TCR) sebesar 68,91\%. Hal ini menunjukkan kepuasan nasabah masuk dalam kategori cukup. Dengan demikian disimpulkan nasabah mempunyai tingkat kepuasan yang cukup atas dimensi kepuasan nasabah pada PT. Bank Rakyat Indonesia Cabang Padang. 


\section{Analisis Data Hasil Penelitian}

\section{Uji Persyaratan Analisis (Uji Asumsi Klasik) \\ Uji Normalitas}

Pengujian normalitas data dilakukan dengan menggunakan teknik Uji Kolmogorov Smirnov (Uji K-S) dan sebagai dasar penolakan atau penerimaan keputusan normal tidaknya distribusi data ditetapkan pada taraf signifikan alpha 0,05. Hasil perhitungan uji normalitas didapatkan normal dapat dilihat pada tabel sebagai berikut:

Tabel 13

Uji Normalitas

\begin{tabular}{|c|l|c|c|c|}
\hline No & \multicolumn{1}{|c|}{ Variabel } & Sig & Alpha & Keterangan \\
\hline 1 & Tangible & 0,087 & 0,05 & Normal \\
\hline 2 & Reliability & 0,367 & 0,05 & Normal \\
\hline 3 & Resposiveness & 0,256 & 0,05 & Normal \\
\hline 4 & Assurance & 0,099 & 0,05 & Normal \\
\hline 5 & Empathy & 0,294 & 0,05 & Normal \\
\hline 6 & Kepuasan Nasabah & 0,123 & 0,05 & Normal \\
\hline 7 & Loyalitas Nasabah & 0,422 & 0,05 & Normal \\
\hline
\end{tabular}

Sumber: Pengolahan data primer, 2013

Berdasarkan tabel diatas terlihat bahwa nilai sig. Untuk semua variabel adalah lebih besar dari 0,05. Dengan demikian data berdistribusi normal, atua uji normalitas terpenuhi sehingga analisis jalur dapat dilakukan.

\section{Uji Homogenitas}

Uji homoqenitas adalah uji yang dilakukan untuk melihat apakah data yang diperoleh berasal dari sampel yang homogen. Uji homogenitas variansi populasi dilakukan dengan Test Homogeneity of Variance pada nilai alpha 0,05. Hasil perhitungan untuk uji homogenitas dapat dilihat pada tabel sebagai berikut:

\section{Tabel 14}

\section{Uji Homogenitas}

\begin{tabular}{|c|l|c|c|c|c|c|}
\hline No & \multicolumn{1}{|c|}{ Variabel } & $\begin{array}{c}\text { Levene } \\
\text { Statistic }\end{array}$ & df1 & df2 & Sig. & Keterangan \\
\hline 1 & Tangible & 1,061 & 26 & 264 & 0,242 & Normal \\
\hline 2 & Reliability & 1,278 & 26 & 264 & 0,136 & Normal \\
\hline 3 & Responsiveness & 1,177 & 26 & 264 & 0,257 & Normal \\
\hline 4 & Assurance & 1,260 & 26 & 264 & 0,185 & Normal \\
\hline 5 & Empathy & 1,301 & 26 & 264 & 0,155 & Normal \\
\hline 6 & Kepuasan Nasabah & 1,092 & 26 & 264 & 0,350 & Normal \\
\hline
\end{tabular}

Sumber: Pengolahan data primer, (2013)

Berdasarkan hasil analisis untuk uji homogenitas sebagaimana yang terlihat pada tabel diatas terlihat bahwa nilai sig. untuk semua variabel lebih besar dari tingkat signifikan yang digunakan 0,05. Dengan demikian dapat diartikan bahwa sebaran data berasal dan sampel yang homogen sehingga analisis jalur dapat dilakukan. 


\section{Analisis Jalur}

\section{Analisis Jalur Sub Struktur 1}

Pada analisis sub struktur pertama akan dilihat pengaruh dari variabet kualitas pelayanan terhadap kepuasan nasabah. Dan struktur analisis jalur akan dilakukan analisis untuk mengetahui tingkat signifikansi dan koefisien jalur dari masing-masing variabel bebas terhadap variabel akibat baik yang bersifat langsung maupun tidak langsung dengan bantuan software SPSS V.13.00.

\section{Uji F}

Tabel 15

ANOVA

\begin{tabular}{|l|l|l|c|c|c|c|}
\hline \multicolumn{2}{|c|}{ Model } & Sum of Square & df & $\begin{array}{c}\text { Mean } \\
\text { Square }\end{array}$ & F & Sig. \\
\hline 1 & Regression & 3445.994 & 5 & 689.199 & 91.854 & $.000(\mathrm{a})$ \\
& Residual & 2153.426 & 287 & 7.503 & & \\
& Total & 5599.420 & 292 & & & \\
\hline
\end{tabular}

Sumber: Pengolahan data primer, (2013)

Berdasarkan uji F diketahui bahwa nilai F hitung 91,854 dengan nilai Sig sebesar 0.000. Jika dibandinakan dengan tingkat signifikan yang digunakan pada penelitian ini $(a=0,05)$ maka terbukti bahwa nilai signifikansi lebih kecil dari tingkat signifikannya $(0.000<0,05)$, hal ini berarti secara bersama-sama semua variabel penyebab $(\mathrm{X})$ berpengaruh secara signifikan terhadap variabel akibat $(\mathrm{Y})$, sehingga dapat dilanjutkan untuk pengujian secara individual.

Uji $t$

Tabel 16

Koefisien Jalur

\begin{tabular}{|l|l|c|c|c|}
\hline \multirow{2}{*}{ Model } & Standardized Coefficient & \multirow{2}{*}{$\mathrm{t}$} & \multirow{2}{*}{ Sig. } \\
\cline { 3 - 3 } & Beta & & \\
\hline & Tangible & 0,121 & 2,603 & 0,010 \\
\hline & Reliability & 0,280 & 5,874 & 0,000 \\
\hline & Responsiveness & 0,404 & 8,376 & 0,000 \\
\hline & Assurance & 0,118 & 2,751 & 0,006 \\
\hline & Empathy & 0,083 & 2,014 & 0,045 \\
\hline
\end{tabular}

Sumber: Pengolahan data primer, (2013)

Pada tabel diatas terlihat bahwa nilai signifikansi dan semua variabel lebih kecil dari tingkat signifikannya, hal ini berarti semua variabel penyebab berpengaruh secara signifikan terhadap variabel akibat. Dengan demikian tidak ada variabel yang dikeluarkan dari sub struktur karena semuanya mempunyai pengaruh yang signifikan terhadap variabel dependen.

Tabel 17

Rekapitulasi Pengaruh Langsung dan Tidak Langsung Variabel Kualitas Layanan Terhadap Kepuasan Nasabah

\begin{tabular}{|c|l|c|}
\hline No & \multicolumn{1}{|c|}{ Keterangan } & Besar Pengaruh (\%) \\
\hline 1 & Pengaruh X1 terhadap X6 & 6,62 \\
\hline 2 & Pengaruh X2 terhadap X6 & 16,30 \\
\hline 3 & Pengaruh X3 terhadap X6 & 21,75 \\
\hline 4 & Pengaruh X4 terhadap X6 & 5,42 \\
\hline 5 & Pengaruh X5 terhadap X6 & 3,08 \\
\hline
\end{tabular}

Sumber: Pengolahan data primer, 2013 


\section{Analisis Jalur Sub Struktur 2}

Pada analisis sub struktur pertama akan dilihat pengaruh dari variabel kualitas pelayanan dan kepuasan nasabah terhadap loyalitas nasabah. Dari struktur analisis jalur akan dilakukan analisis untuk mengetahui tingkat signifikansi dan koefisien jalur dari masing-masing variabel bebas terhadap variabel akibat baik yang bersifat langsung maupun tidak langsung. Dengan bantuan software SPSS V.13.00 dalam melakukan pengolahan data untuk sub struktur 2 dari analisis jalur ini dapat diperoleh nilai-nilai sebagai berikut:

\section{Uji F}

Tabel 18

ANOVA

\begin{tabular}{|l|l|c|c|c|c|c|}
\hline \multicolumn{2}{|c|}{ Model } & Sum of Square & df & $\begin{array}{c}\text { Mean } \\
\text { Square }\end{array}$ & F & Sig. \\
\hline 1 & Regression & 6213.990 & 6 & 1035.665 & 57.434 & $.000(\mathrm{a})$ \\
& Residual & 5157.198 & 286 & 18.032 & & \\
& Total & 11371.188 & 292 & & & \\
\hline
\end{tabular}

Sumber: Pengolahan data primer, 2013

Berdasarkan uji F diketahui bahwa nilai F hitung 57,843 dengan nilai Sig sebesar 0.000. Jika dibandinakan dengan tingkat signifikan yang digunakan pada penelitian ini $(a=0,05)$ maka terbukti bahwa nilai signifikansi lebih kecil dari tingkat signifikannya $(0.000<0,05)$, hal ini berarti secara bersama-sama semua variabel penyebab $(\mathrm{X})$ berpengaruh secara signifikan terhadap variabel akibat (Y), sehingga dapat dilanjutkan untuk pengujian secara individual.

Uji $t$

Tabel 19

Koefisien Jalur

\begin{tabular}{|l|l|c|c|c|}
\hline \multirow{2}{*}{ Model } & $\begin{array}{c}\text { Standardized } \\
\text { Coefficient }\end{array}$ & \multirow{2}{*}{$\mathrm{t}$} & \multirow{2}{*}{ Sig. } \\
\cline { 3 - 3 } \multicolumn{2}{|c|}{} & Beta & & \\
\hline & Tangible & 0,110 & 2,152 & 0,032 \\
\hline & Reliability & 0,138 & 2,510 & 0,013 \\
\hline & Responsiveness & 0,126 & 2,156 & 0,030 \\
\hline & Assurance & 0,139 & 2,962 & 0,003 \\
\hline & Empathy & 0,186 & 4,107 & 0,000 \\
\hline & Kepuasan Nasabah & 0,285 & 4,432 & 0,000 \\
\hline
\end{tabular}

Sumber: Pengolahan data primer, 2013

Pada tabel diatas terlihat bahwa nilai signifikansi dan semua variabel lebih kecil dari tingkat signifikannya, hal ini berarti semua variabel penyebab berpengaruh secara signifikan terhadap variabel akibat. Dengan demikian tidak ada variabel yang dikeluarkan dari sub struktur karena semuanya mempunyai pengaruh yang signifikan terhadap variabel dependen. 
Tabel 20

Rekapitulasi Pengaruh Langsung dan Tidak Langsung Variabel Kualitas Layanan dan Kepuasan Nasabah terhadap Loyalitas Nasabah

\begin{tabular}{|c|l|c|}
\hline No & \multicolumn{1}{|c|}{ Keterangan } & Besar Pengaruh (\%) \\
\hline 1 & Pengaruh X1 terhadap Y & 4,51 \\
\hline 2 & Pengaruh X2 terhadap Y & 5,81 \\
\hline 3 & Pengaruh X3 terhadap Y & 5,60 \\
\hline 4 & Pengaruh X4 terhadap Y & 4,79 \\
\hline 5 & Pengaruh X5 terhadap Y & 5,19 \\
\hline 6 & Pengaruh X6 terhadap Y & 6,61 \\
\hline
\end{tabular}

Sumber: Pengolahan data primer, 2013

\section{PEMBAHASAN}

Pengaruh Kualitas Pelayanan terhadap Kepuasan Nasabah Pada PT Bank Rakyat Indonesia Cabang Padang

Berdasarkan pengujian hipotesis pertama diketahui bahwa terdapat pengaruh yang signifikan dari Tangibles (Bukti Fisik), Reliability (Keandalan), Responsiveness (Daya Tanggap), Assurance (Jaminan), dan Empathy (Empati) terhadap kepuasan pelanggan pada PT Bank Rakyat Indonesia Cabanp Padang. Hal ini menunjukkan bahwa semakin baik kualitas layanan yang diberikan oleh pihak Bank PT Bank Rakvat Indonesia Cabang Padang akan dapat meningkatkan kepuasan nasabah terhadap PT Bank Rakvat Indonesia Cabang Padang.

Temuan penelitian ini konsisten dengan temuan penelitian yang dilakukan oleh Adi (2008) yang melakukan penelitian tentang analisis pengaruh kualitas pelayanan terhadap kepuasan nasabah BMT Kaffah Yogyakarta yang menyimpulkan bahwa kualitas pelayanan berpengaruh positif dan signifikan terhadap kepuasan nasabah, dimana dengan semakin baiknya kualitas pelayanan yang dirasakan oleh nasabah akan meningkatkan kepuasan nasabah.

Hasil penelitian ini didukung oleh pendapat Tjiptono (1996:54) "kualitas pelayanan mempunyai hubungan yang erat dengan kepuasan pelanggan. Kualitas memberikan suatu dengan kepuasan pelanggan. Kualitas memberikan suatu dorongan kepada pelanggan untuk menjalin hubungan yang kuat dengan perusahaan". Pada jangka panjang ikatan seperti ini memungkinkan perusahaan untuk memahami harapan serta kebutuhan pelanggan. Dengan demikian perusahaan dapat meningkatkan kepuasan pelanggan dimana perusahaan memaksimalkan pengalaman pelanggan yang menyenangkan dan meminimalkan pengalaman pelanggan yang kurang menyenangkan.

Suprapto (1980:44) menyatakan bahwa kepuasan pelanggan akan tercapai jika mengkonsumsi barang atau jasa, hasil yang dirasakan pelanggan memenuhi atau melampaui harapannya maka ia akan memutuskan untuk membeli ulang (berlangganan). Kepuasan pelanggan adalah persepsi pelanggan mengenai mutu suatu barang atau jasa dan kepuasan menyeluruh, mereka memiliki beberapa indikator/petunjuk yang bisa dilihat. Pelanggan akan mengatakan hal-hal yang bagus tentang barang atau jasa dan tersenyum ketika berbicara mengenai barang atau jasa.

Pengaruh Kualitas Pelayanan terhadap Loyalitas Nasabah Pada PT Bank Rakyat Indonesia Cabang Padang

Berdasarkan pengujian hipotesis kedua diketahui bahwa terdapat pengaruh 
yang signifikan dari Tangibles (Bukti Fisik), Reliability (Keandalan), Responsiveness (Daya Tanggap), Assurance (Jaminan), Empathy (Empati) dan Kepuasan Nasabah terhadap loyalitas nasabah pada PT Bank Rakyat Indonesia Cabang Padang. Jadi dan temuan penelitian ini memberikan implikasi bahwa dalam mengambil kebijakan untuk meningkatkan loyalitas nasabah manajemen PT Bank Rakyat Indonesia Cabang Padang memperhatikan kualitas pelayanan beserta dimensinya dan kepuasan nasabah.

Temuan penelitian ini konsisten dengan temuan penelitian Palilati (2007) yang meneliti tentang pengaruh nilai pelanggan, kepuasan terhadap loyalitas nasabah tabungan perbankan di Sulawesi Selatan. Temuan penelitiannya membuktikan bahwa kepuasan nasabah berpengaruh terhadap loyalitas nasabah.

Temuan penelitian ini juga didukung oleh hasil penelitian Yani (2004) yang melakukan penelitian tentang analisis pengaruh kualitas pelayanan terhadap loyalitas nasabah PT. Bank Sumut di Medan. Dimana hasil penelitianya menyimpulkan bahwa kualitas pelayanan berpengaruh positif dan signifikan terhadap loyalitas nasabah.

Temuan penelitian ini juga didukung oleh pendapat Kotler (1997) yang menyatakan bahwa bagi konsumen yang terpuaskan akan menjadi pelanggan, sehingga mereka akan:

a. Melakukan pembelian ulang (melakukan transaksi kembali).

b. Mengatakan hal-hal yang baik tentang perusahaan kepada orang lain.

c. Kurang memperhatikan merek ataupun iklan produk pesaing.

d. Membeli produk yang lain dan perusahaan yang sama.

\section{KESIMPULAN}

Berdasarkan hasil pembahasan yang telah dilakukan sebelumnya, maka dapat diambil beberapa kesimpulan sebagai berikut :

1. Loyalitas nasabah pada PT Bank Rakyat Indonesia Cabang Padang masih tergolong cukup yang dipengaruhi oleh variabel kualitas pelayanan atas tangible dalam katesori cukup, kualitas pelayanan atas reliability dalam kategori baik, kualitas pelayanan atas responsiveness dalam kategori cukup, kualitas pelayanan atas assurance dalam kategori cukup, kualitas pelayanan atas empathy dalam kategori cukup dan variabel kepuasan nasabah dalam katesori cukup.

2. Terdapat pengaruh yang signifikan dari tangible (X1), reliability (X2), responsiveness (X3), assurance (X4) dan empathy (X5) terhadap kepuasan pelanggan pada PT Bank Rakyat Indonesia Cabang Padang. Besarnya pengaruh dari kualitas pelayanan (tangible, reliability, responsiveness, assurance dan empathy) terhadap kepuasan nasabah adalah sebesar $61,5 \%$ dan sisanya sebesar $38,5 \%$ dipengaruhi oleh variabel lain yang tidak dimasukkan ke dalam model penelitian.

3. Terdapat pengaruh yang signifikan dari tangible (X1), reliability (X2), responsiveness (X3), assurance (X4) dan empathy (X5) dan kepuasan nasabah (X6) terhadap loyalitas nasabah pada PT Bank Rakyat Indonesia Cabang Padang. Besarnya pengaruh dari kualitas pelayanan (tangible, reliability, responsiveness, assurance dan empathy) dan kepuasan nasabah terhadap loyalitas nasabah adalah sebesar $54,6 \%$ dan sisanya sebesar 45,4\% dipengaruhi oleh variabel lain yang tidak masuk kedalam model penelitian. 


\section{DAFTAR PUSTAKA}

Aziz, N. (2019). Pengaruh Kualitas Layanan Terhadap Kepuasan Nasabah SMS Banking Pada Bank Nagari Cabang Pembantu RSUP DR M Djamil Padang. https://doi.org/10.17605/OSF.IO/S3JVG

Aziz, N. (2019). Pengaruh Biaya, Angsuran Dan Kualitas Pelayanan Terhadap Kepuasan Nasabah Pembiayaan Bmt At-Taqwa Muhammadiyah Cabang Siteba Padang. https://doi.org/10.17605/OSF.IO/YVJAS

Fernandes, Y. D., \& Marlius, D. (2018). Peranan Customer Service Dalam Meningkatkan Pelayanan Kepada Nasabah Pada PT. Bank Pembangunan Daerah Sumatera Barat Cabang Utama Padang. https://doi.org/10.31227/osf.io/wrh3p

Hurriyati, Ratih. 2005. Bauran Pemasaran dan Loyalitas Konsumen. Bandung: Alfabeta

Kertajaya, Hermawan. 2005. MarkPlus on Strategy, 12 Tahun Perjalanan MarkPlus\&Co, Membangun Strategi Perusahaan. Jakarta: PT. Gramedia Pustaka Utama.

Kotler, Philip dkk. 1997. Manajemen Pemasaran, Analisis, Perencanaan, Implementasi dan Kontrol. Terjemahan Hendro Teguh dan RA. Rusli. Jakarta: PT. Prenhallindo

Kotler, Philip dkk. 2002. Manajemen Pemasaran Edisi Milenium. Jakarta: PT. Prenhallindo.

Marlius, D. (2018). Pengaruh Dimensi Kualitas Pelayanan Website Akademik Terhadap Kepuasan Mahasiswa Pada STIE “KBP”. Jurnal Ipteks Terapan. $\begin{array}{lllll}\text { Volume } & 12 . & \text { No. } & 2 . & \text { Hal. }\end{array}$ http://doi.org/10.22216/jit.2018.v12i2.633

Marlius, D. (2018). Loyalitas Nasabah Bank Nagari Syariah Cabang Bukittinggi Dilihat Dari Kualitas Pelayanan. Jurnal Pundi. Volume 1. No. 3. Hal.1222. https://doi.org/10.31575/jp.v1i3.60

Mayliza, R. (2019). Pengaruh Citra Perusahaan (Corporate Image) Dan Penanganan Keluhan (Complaint Handling) Terhadap Loyalitas Pelanggan (Loyality) Natasha Skin Care Di Kota Padang. https://doi.org/10.17605/OSF.IO/DF9XJ

Mayliza, R. (2019). Pengaruh Kesadaran Merek, Asosiasi Merek Dan Perception Of Quality Terhadap Keputusan Pembelian Hospital Bed Merek Paramout Di PT. Aga Medika Utama Padang (Studi Kasus Rumah Sakit Umum Kota Padang). https://doi.org/10.17605/OSF.IO/VYQ4E 
Mirawati \& Fernos, J. (2019). Peranan Customer Service Dalam Meningkatkan Pelayanan Terhadap Nasabah Pada Bank Nagari Cabang Siteba Padang. https://doi.org/10.31227/osf.io/cq458

Putra, A. M., \& Fernos, J. (2019). Pelaksanaan Pelayanan Prima Terhadap Kepercayaan Nasabah Di PT. Bank Perkreditan Rakyat Jorong Kampung Tangah Pariaman. https://doi.org/10.31227/osf.io/c3fy4

Safitri, R. N., \& Marlius, D. (2017). Penerapan E-Banking Dalam Meningkatkan Jasa Dan Layanan Perbankan Di PT. Bank Rakyat Indonesia Cabang Padang. https://doi.org/10.31227/osf.io/gkv8t

Suprapto. 1980. Pengukuran Tingkat Kepuasan Pelanggan untuk Menaikkan Pangsa Pasar,

Susanti, F. W Ekazaputri. (2018). Service Performance Dan Kepuasan Sebagai Moderating Variabel Terhadap Loyalitas Nasabah Pada PT BPR Labuh Gunung Payakumbuh Jurnal Benefita: Ekonomi Pembangunan Manajemen Bisnis Dan Akuntansi. Volume 3. No. 3. Hal. 433444.http://doi.org/10.22216/jbe.v3i3.3472

Tiza, M. F., \& Susanti, F. (2019). Pengaruh Kualitas Pelayanan Terhadap Kepuasan Pelanggan, Studi kasus pada perusahaan JNE Cabang Padang. https://doi.org/10.31227/osf.io/hx87m

Tjiptono, Fandy. 1996. Strategi Pemasaran. Yogyakarta: Andi Offset 2000. Management Jasa. Yogyakarta: Andi Offset

Ulfa, M., \& Mayliza, R. (2019). Pengaruh Kualitas Pelayanan Dan Kepuasan Pelanggan Terhadap Loyalitas Pelanggan PDAM Kota Padang. https://doi.org/10.31219/osf.io/spmgv 